\title{
STRENGTH ANALYSIS OF A TELESCOPIC HYDRAULIC CYLINDER ELASTICALLY MOUNTED ON BOTH ENDS
}

\author{
Sebastian Uzny, Lukasz, Kutrowski \\ Institute of Mechanics and Machine Design Fundamentals, Czestochowa University of Technology \\ Czestochowa, Poland \\ uzny@imipkm.pcz.pl,kutrowski@imipkm.pcz.pl
}

Received: 5 February 2019; Accepted: 2 April 2019

\begin{abstract}
Corrosion or contamination of flexible joints of a telescopic hydraulic cylinder may cause an increase of movement resistance in these places. In this work the influence of mounting rigidity on the strength of a telescopic hydraulic cylinder is under consideration. Buckling criterion and the strength of cylinder barrels (material effort) were included due to analysis. Boundary value problem concerning the stability of the system was formulated on the basis of the static stability criterion. Lame's theory for thick pipes were used for determination of destructive load from the viewpoint of the material effort. Numerical simulations were performed. The results specifying the influence of mounting rigidity on stability and strength of cylinder barrels were presented by using non-dimensional parameters.
\end{abstract}

MSC 2010: 74H55, 65L10

Keywords: stability, hydraulic telescopic cylinder, Euler's load, material effort

\section{Introduction}

Cylinders are widely used in different industrial branches. Structures, which have a hydraulic drive system, are characterized by high working forces and low working speed. Because of their construction, they are strongly exposed to damage due to loss of stability. Another aspect, which decides of cylinder damage, is the material effort of the cylinder barrels, caused by high pressure of hydraulic oil. If cylinders are used in machines, which can be exposed to vibrations, another examination should be performed - free vibrations analysis. In this case characteristic curves on the plane "critical load - vibration frequency" should be determined. Free vibration frequency consists of carrying load and coverage level.

Stability analysis of hydraulic cylinders were performed in works [1-10]. Comparison between the results of numerical simulations (FEM) and recommendations in DNV GL were presented in position [1]. In paper [2] theoretical model of onestage hydraulic cylinder was presented and number of parameters of the system which have high impact on stability of hydraulic cylinder were under considera- 
tion. The influence of inaccuracies in joints between the piston and cylinder barrel were analysed numerically and experimentally in work [3]. In paper [4] a physical and mathematical model of a hydraulic prop, whose construction corresponds to one-stage hydraulic cylinder was presented. Regions of the flexural rigidity asymmetry factor for the piston rod and cylinder where the system is subject to damage as a result of stability loss and material effort were presented in work [5]. The influence of mounting rigidity in the case of a one-stage hydraulic cylinder were analysed in work [6]. In paper [7] the stiffness model of hydraulic cylinder was defined. The model takes into account elasticity of hydraulic oil, the presence of air bubbles in hydraulic oil, axial deformations of piston rod, volumetric expansion of cylinder barrel, metal pipes, power pipes and deformation of sealing elements. Results of experimental tests and forecasting method for fatigue fracture of hydraulic cylinders were presented in paper [8]. Results of numerical and experimental tests of one-stage hydraulic cylinder elastically mounted on both ends in regards to the stability and free vibrations were shown in work [9]. Papers $[10,11]$ revolve around the stability of a hydraulic telescopic cylinder. The influence of stiffness between the following elements of the cylinder on the stability of the system were presented in work [10]. Regions of the system parameters, in which telescopic hydraulic cylinder can be damaged due to loss of stability and material effort, were presented. The influence of the cylinder barrel thickness parameter and sealing element thickness parameter on the stability and strength of each member of the telescopic hydraulic cylinder were under consideration in paper [11].

This work includes numerical simulations on influence of mounting rigidity on stability of the telescopic hydraulic cylinder. Changes of this parameter can be caused by corrosion, dirt, and seizure the joints. Three possible changes of stiffness parameter were analysed in this paper: increase of lower mounting stiffness, increase of upper mounting stiffness and increase of both mounting stiffness.

\section{Formulation of boundary value problem}

In this work, the boundary problem of stability of hydraulic telescopic cylinder with particular emphasis on mounting rigidity is under consideration. The considered system is presented in Figure 1. It consists of $n$ elements, where elements marked from 1 to $(n-1)$ are the cylinder barrels and the element marked as $n$ is a piston rod. Each element of the cylinder is characterised by flexural rigidity $(E J)_{i}$. In this model, stiffness of sealing and guiding elements were taken into consideration. This stiffness is modelled by rotational springs $C_{R}$. Stiffness between following elements were assumed as equal. This system is analysed as a fully-extended in this case hydraulic telescopic cylinder is characterised by the smallest slenderness ratio and the smallest stiffness. Construction is mounted elastically on both ends. Mounting rigidity of lower and upper end of the cylinder are realised by rotational springs $C_{R 0}$ and $C_{R n}$. In this work hydraulic telescopic cylinder is built on the basis of the total length of the system $l_{C}$ and diameter of piston $\operatorname{rod} d_{t}$. Diameters 
of sealing and guiding elements and lengths of each cylinder are assumed to be constant and on the basis of that assumptions next element diameters of the system are calculated.
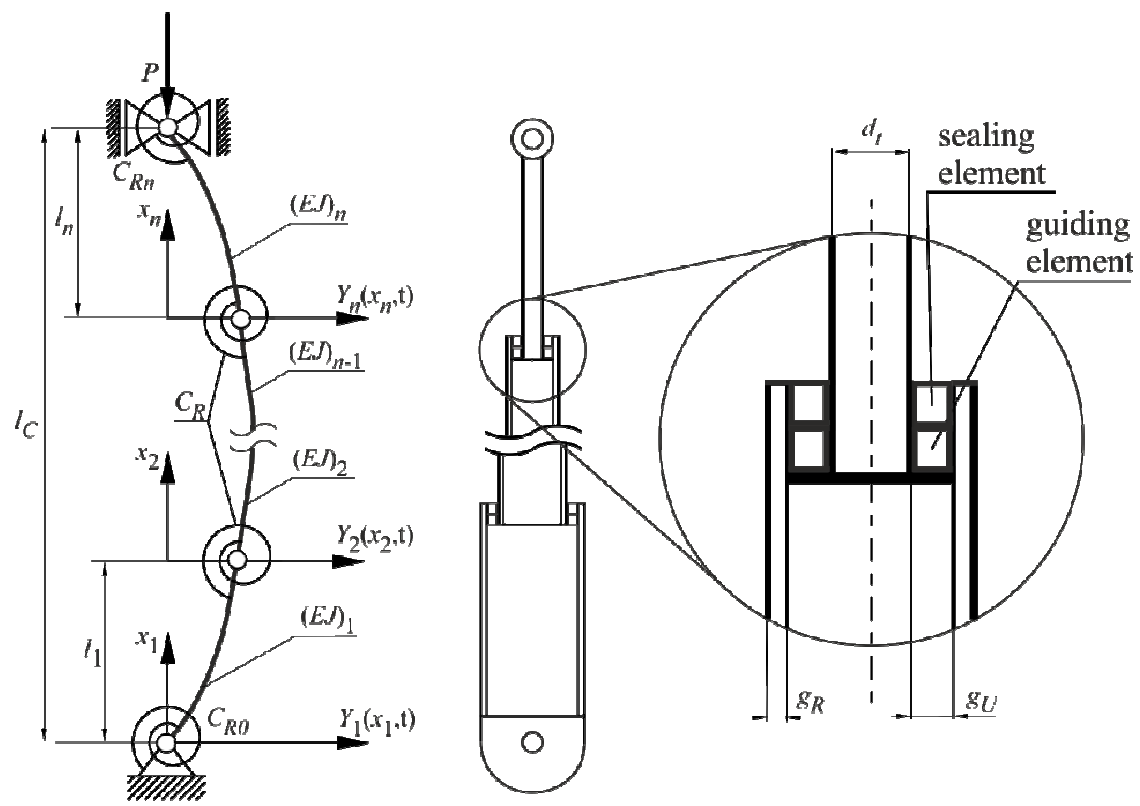

Fig. 1. Scheme of hydraulic telescopic cylinder under Euler's load

By using the static stability criterion, boundary problem were formulated. Total potential energy of the system consists of the bending elasticity energy of each element, energy coming from the external load and energy of each discreet element (rotational springs $C_{R 0}, C_{R}, C_{R n}$ ):

$$
\begin{aligned}
V= & \frac{1}{2} \sum_{i=1}^{n} \int_{0}^{l_{i}}(E J)_{i}\left(\frac{d^{2} w_{i}\left(x_{i}\right)}{d x_{i}^{2}}\right)^{2} d x_{i}-\frac{1}{2} P \sum_{i=1}^{n} \int_{0}^{l_{i}}\left(\frac{d w_{i}\left(x_{i}\right)}{d x_{i}}\right)^{2} d x_{i}+\frac{1}{2} C_{R 0}\left(\left.\frac{d w_{1}\left(x_{1}\right)}{d x_{1}}\right|_{x_{1}=0}\right)^{2}+ \\
& +\frac{1}{2} C_{R n}\left(\left.\frac{d w_{n}\left(x_{n}\right)}{d x_{n}}\right|^{x_{n}=l_{n}}\right)^{2}+\frac{1}{2} C_{R} \sum_{i=1}^{n} \int_{0}^{l_{i}}\left[\left.\frac{d w_{i}\left(x_{i}\right)}{d x_{i}}\right|^{x_{i}=l_{i}}-\left.\frac{d w_{i+1}\left(x_{i+1}\right)}{d x_{i+1}}\right|_{x_{i+1}=0}\right]^{2} d x_{i}
\end{aligned}
$$

In this case the boundary conditions can be written in form:

$$
\begin{gathered}
w_{i}\left(l_{i}\right)=w_{i+1}(0) \\
w_{1}(0)=0 \\
w_{n}\left(l_{n}\right)=0
\end{gathered}
$$


After appropriate mathematical transformations, equations of transversal displacement are presented as follows:

$$
(E J)_{i} \frac{d^{4} w_{i}\left(x_{i}\right)}{d x_{i}^{4}}+P \frac{d^{2} w_{i}\left(x_{i}\right)}{d x_{i}^{2}}=0
$$

Natural boundary conditions of the analysed system can be written in form:

$$
\begin{gathered}
\left.(E J)_{i} \frac{d^{2} w_{i}\left(x_{i}\right)}{d x_{i}^{2}}\right|^{x_{i}=l_{i}}+C_{R}\left[\left.\frac{d w_{i}\left(x_{i}\right)}{d x_{i}}\right|^{x_{i}=l_{i}}-\left.\frac{d w_{i+1}\left(x_{i+1}\right)}{d x_{i+1}}\right|_{x_{i+1}=0}\right]=0 \\
-\left.(E J)_{i+1} \frac{d^{2} w_{i+1}\left(x_{i+1}\right)}{d x_{i+1}{ }^{2}}\right|_{x_{i+1}=0}-C_{R}\left[\left.\frac{d w_{i}\left(x_{i}\right)}{d x_{i}}\right|^{x_{i}=l_{i}}-\left.\frac{d w_{i+1}\left(x_{i+1}\right)}{d x_{i+1}}\right|_{x_{i+1}=0}\right]=0 \\
-\left.(E J)_{i} \frac{d^{3} w_{i}\left(x_{i}\right)}{d x_{i}^{3}}\right|^{x_{i}=l_{i}}+\left.(E J)_{i+1} \frac{d^{3} w_{i+1}\left(x_{i+1}\right)}{d x_{i+1}{ }^{3}}\right|_{x_{i+1}=0}-\left.P \frac{d w_{i}\left(x_{i}\right)}{d x_{i}}\right|^{x_{i}=l_{i}}+\left.P \frac{d w_{i+1}\left(x_{i+1}\right)}{d x_{i+1}}\right|_{x_{i+1}=0}=0 \\
-\left.(E J)_{1} \frac{d^{2} w_{1}\left(x_{1}\right)}{d x_{1}^{2}}\right|_{x=0}+\left.C_{R 0} \frac{d w_{1}\left(x_{1}\right)}{d x_{1}}\right|_{x=0} ^{=0}=0 \\
\left.(E J)_{n} \frac{d^{2} w_{n}\left(x_{n}\right)}{d x_{n}^{2}}\right|^{x_{n}=l_{n}}+\left.C_{R n} \frac{d w_{n}\left(x_{n}\right)}{d x_{n}}\right|^{x_{n}=l_{n}}=0
\end{gathered}
$$

The solution of equations of transversal displacement (5) can be written as follows:

$$
w_{i}\left(x_{i}\right)=A_{i} \sin \left(k_{i} x_{i}\right)+B_{i} \cos \left(k_{i} x_{i}\right)+C_{i} x_{i}+D_{i}
$$

where $k_{i}=\sqrt{\frac{P}{(E J)_{i}}}$.

Taking into account the solution (11) in boundary conditions ((2)-(4), (6)-(10)), the system of equations is obtained. The determinant matrix of the coefficients of a system of equations equated to zero leads to the transcendental equation, from which the critical load of the system can be determined.

\section{Material effort problem}

Effort of cylinder material, next to buckling, is one of the crucial factors, that effects the capacity of hydraulic telescopic cylinders. Cylinder barrels of a tele- 
scopic hydraulic cylinder can be treated as thick pipes closed by lids. This case describes a situation when the external load of the telescopic cylinder is balanced by the pressure of the hydraulic oil inside the system. Radial and circumferential stresses by Lamé's theory can be obtained on the basis of following relations [12]:

$$
\begin{gathered}
\sigma_{r}=\frac{p_{a} r_{w}{ }^{2}}{r_{z}^{2}-r_{w}{ }^{2}}\left(1-\frac{r_{z}^{2}}{r^{2}}\right) \\
\sigma_{t}=\frac{p_{a} r_{w}{ }^{2}}{r_{z}^{2}-r_{w}{ }^{2}}\left(1+\frac{r_{z}^{2}}{r^{2}}\right)
\end{gathered}
$$

where: $p_{a}$ - pressure inside the cylinder, $r_{w}$ - internal radius of cylinder, $r_{z}$ - external radius of cylinder, $r$ - distance between an axis and layer of cylinder, where the stresses are calculated.

By using Huber's hypothesis, reduced stresses of thick-walled cylinder can be determined from following equation [12]:

$$
\sigma_{\text {red }}=\frac{p_{a} r_{w}{ }^{2}}{r_{z}{ }^{2}-r_{w}{ }^{2}} \sqrt{1+3\left(\frac{r_{z}}{r}\right)^{4}}
$$

The maximal value of reduced stresses occurs on the internal layer of the cylinder. In this work, it is assumed that the maximum acceptable stress is known and is equal to the yield point of the cylinder material. When the maximum stresses achieve the value of yield point, permanent deformations occurs in the cylinders, which cause the damage of the hydraulic cylinder. After transformations of the equations (14), the maximal value of pressure (15) and the maximal value of external load from the viewpoint of material effort (16) was calculated:

$$
\begin{gathered}
p_{\max }=\frac{\sigma_{r e d}\left(r_{z}{ }^{2}-r_{w}{ }^{2}\right)}{r_{w}{ }^{2} \sqrt{1+3\left(\frac{r_{z}}{r_{w}}\right)^{4}}} \\
P_{\sigma}=p_{\max } \pi r_{w}{ }^{2}
\end{gathered}
$$

\section{Results of numerical simulations}

The influence of mounting rigidity of hydraulic telescopic cylinder on its strength is under consideration in this work. On the basis of the formulated boundary problem, the critical load of the system in regards to the buckling phenomenon was determined. By using Lamé's theory for thick pipes, destructive load from 
the viewpoint of material effort was calculated. Non-dimensional parameters were defined:

$$
\begin{gathered}
\zeta_{G U}=\frac{g_{U}}{d_{t}} ; \zeta_{G R}=\frac{g_{R}}{d_{t}} ; \zeta_{L}=\frac{l_{C}}{d_{t}} ; \zeta_{C R}=\frac{C_{R} l_{C}}{(E J)_{n}} ; \lambda_{w y b}=\frac{P_{w y b} l_{C}^{2}}{(E J)_{n}} ; \\
\lambda_{\sigma}=\frac{P_{\sigma} l_{C}^{2}}{(E J)_{n}} ; \zeta_{C R 0}=\frac{C_{R 0} l_{C}}{(E J)_{n}} ; \zeta_{C R n}=\frac{C_{R n} l_{C}}{(E J)_{n}}
\end{gathered}
$$

where: $\zeta_{G U}$ - parameter of sealing and guiding elements thickness, $\zeta_{G R}$ - parameter of cylinder barrels thickness, $\zeta_{L}$ - parameter of hydraulic telescopic cylinder length, $\zeta_{C R}$ - parameter of stiffness between following elements, $\zeta_{C R 0}$ - parameter of stiffness in lower mounting, $\zeta_{C R n}$ - parameter of stiffness in upper mounting, $\lambda_{c r}$ - parameter of critical load, $\lambda_{\sigma}$ - parameter of destructive load.

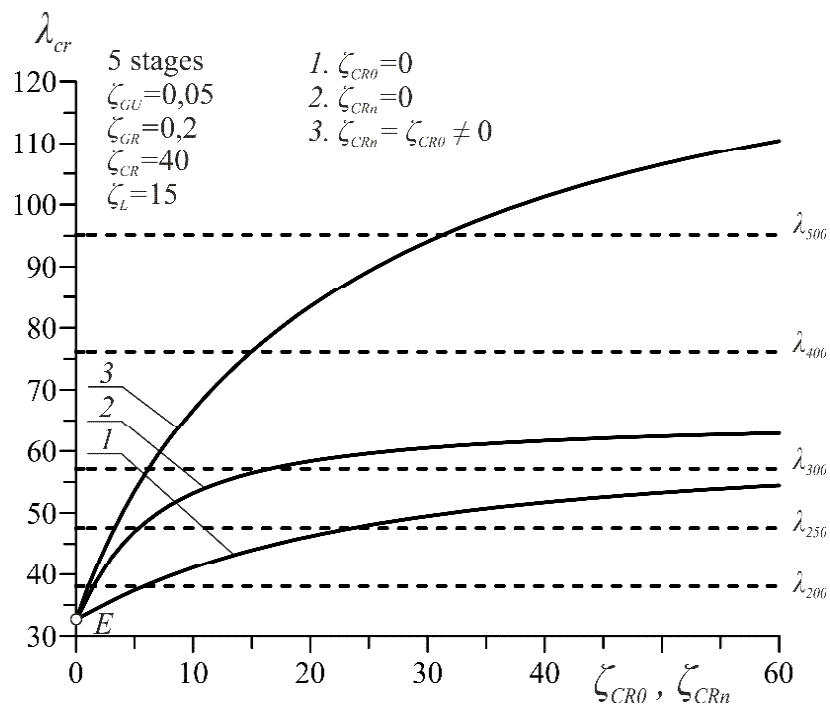

Fig. 2. The influence of mounting rigidity on the critical and destructive load of the system

Results of numerical simulations were presented for a five-stage hydraulic telescopic cylinder. Dependence between stiffness in mounting points (represented by parameters $\zeta_{C R 0}$ and $\zeta_{C R n}$ ) and the maximal capacity of the hydraulic telescopic cylinder is presented in Figure 2. The solid curves characterise the change of parameter of critical load $\left(\lambda_{c r}\right)$ depending on parameters of stiffness in mounting points. The curve number 1 refers to the case, when the upper stiffness increases $\left(\zeta_{C R 0}=0\right.$, $\zeta_{C R n}$ increases). The change of critical load due to an increase of lower mounting rigidity is represented by curve number $2\left(\zeta_{C R n}=0, \zeta_{C R 0}\right.$ increases). The case when both stiffnesses increase ( $\zeta_{C R n}$ and $\zeta_{C R 0}$ increase) at the same time is described by the curve number 3 . 
The strength of the cylinder barrels in the telescopic hydraulic cylinder is under consideration in work [11]. It was demonstrated that the weakest member in regards to the material effort is a cylinder after the piston rod.

Horizontal dashed lines (marked as $\lambda_{200} \ldots \lambda_{500}$ ) determine the values of the destructive load parameter for the weakest cylinder (element number 4 of five-stage hydraulic telescopic cylinder). This lines presents the relations for different acceptable stresses which are equal to $\sigma=200,250,300,400,500 \mathrm{MPa}$.

Point $E$ refers to the situation, when the stiffnesses in mounting points are zero. Then it can be stated that there is no movement resistance in those places.

\section{Conclusions}

Formulation of the boundary value problem in regards to stability of hydraulic telescopic cylinder was presented in this work. In strength analysis of this system, effort of cylinder material was also considered. The influence of mounting rigidity on critical and destructive load of the system was examined.

On the basis of obtained results it was found, that the increase of mounting rigidity increases the buckling capacity of hydraulic telescopic cylinder. In case of the increase of the lower mounting stiffness parameter, the parameter of critical load is characterized by greater values than in the case of the increase of upper mounting stiffness. A much greater increase of parameter of critical load is observed when the elastic mountings are applied on both ends of the cylinder in comparison to elastic mounting only on one end. Intersection points of lines connected with critical and destructive loads define regions of system parameters, in which the damage of the hydraulic telescopic cylinder is caused by buckling and effort of cylinder material.

\section{Acknowledgement}

The study has been carried out within the statutory funds of the Czestochowa University of Technology (BS/MN-1-101-304/17/P and BS/PB 1-101-3020/17/P).

\section{References}

[1] Narvydas, E. (2016). Buckling strength of hydraulic cylinders - and engineering approach and finite element analysis. Mechanika, 22(6), 474-477.

[2] Gómez Rodríguez, V., Cabello Eras, J., Herrera, H., \& Goytisolo Espinosa, R. (2016). Static analysis of a single stage hydraulic cylinder. International Journal of Engineering and Technology, 8(6), 2443-2451.

[3] Gamez-Montero, P.J., Salazar, E., Castilla, R., Freire, J., Khamashta, M., \& Codina, E. (2009). Misalignment effects on the load capacity of a hydraulic cylinder. International Journal of Mechanical Sciences, 51(2), 105-113.

[4] Tomski, L. (1977). Elastic carrying capacity of a hydraulic prop. Engineering Transactions, 25(2), 247-263. 
[5] Tomski, L., \& Uzny, S. (2011). A hydraulic cylinder subjected to Euler's load in aspect of the stability and free vibrations taking into account discrete elastic elements. Archives of Civil and Mechanical Engineering, 11(3), 769-785.

[6] Uzny, S. (2009). Free vibrations and stability of hydraulic cylinder fixed elastically on both ends. Proc. Appl. Math. Mech., 9, 303-304.

[7] Hao, F., Qungui, D., Yuxian, H., \& Yongbin, Ch. (2017). Modelling study on stiffness characteristics of hydraulic cylinder under multi-factors. Strojniški vestnik - Journal of Mechanical Engineering, 63(7-8), 447-456.

[8] Jakubczak, H., \& Rojek, J. (2005). Fatigue fracture of hydraulic cylinders. Diagnostyka, 36, 61-66.

[9] Tomski, L., \& Uzny, S. (2008). Stateczność i drgania swobodne siłownika hydraulicznego sprężyście zamocowanego. Zeszyty Naukowe Politechniki Rzeszowskiej, seria: Mechanika, 258(74), 369-380.

[10] Uzny, S., Sokół, K., \& Kutrowski, Ł. (2017). Stability of a Hydraulic Telescopic Cylinder Subjected to Euler's Load. In: Rusiński, E., Pietrusiak, D. (eds). Proceedings of the 13th International Scientific Conference. Lecture Notes in Mechanical Engineering. Springer.

[11] Uzny, S., \& Kutrowski, Ł. (2018). Obciążalność rozsuniętego teleskopowego siłownika hydraulicznego przy uwzględnieniu wyboczenia oraz wytężenia materiału. Modelowanie Inżynierskie, 37(68), 125-131.

[12] Jakubowicz, A., \& Orłoś, Z. (1978). Wytrzymałość materiałów. Warszawa: WNT. 